\title{
Uso de casos para ensino em turismo: Estratégia de ensino- aprendizagem para a formação superior no Brasil
}

\author{
The use of cases for teaching tourism: Teaching-learning strategy for \\ higher education in Brazil
}

\section{Uso de casos para la enseñanza en el turismo: Estrategia de enseñanza- aprendizaje para la educación superior en Brasil}

\author{
Maria Valéria Pereira de Araújo ${ }^{1}$ \\ Mirian Rejowski ${ }^{2}$ \\ Sérgio Rodrigues Leal ${ }^{3}$
}

Resumo: Estudo exploratório sobre a aplicabilidade de casos para ensino na formação superior enquanto estratégia de ensino-aprendizagem, com o objetivo de estimular os docentes e pesquisadores de Turismo para a construção de casos do turismo brasileiro. Na primeira parte, o trabalho baseia-se em referencial da área de Administração, descrevendo o método do caso e o uso de casos para ensino em seus aspectos conceituais, tradição de aplicação, e formato e viabilidade. Na segunda, apresenta-se um caso-problema do turismo brasileiro com foco em Porto de Galinhas (PE), tratando da evolução desse destino turístico a partir da década de 1980, sua crise com o surto de cólera no estado pernambucano na década seguinte, e o dilema do proprietário de uma pequena pousada ao enfrentar essa crise. Ao final, destaca-se a urgência da construção de casos de ensino do turismo brasileiro para sua aplicação em cursos superiores, ao lado do papel de associações científicas e de periódicos científicos disseminando os mesmos junto a docentes e pesquisadores.

Palavras-chave: Turismo; Formação superior; Casos de ensino; Ensino-aprendizagem; Porto de Galinhas (PE, Brasil).

Abstract: Exploratory study about the applicability of cases for teaching in higher education as a teachinglearning strategy, with the aim of stimulating tourism lecturers and researchers to elaborate cases about

\footnotetext{
${ }^{1}$ Professora Adjunta do Departamento de Ciências Administrativas da Universidade Federal do Rio Grande do Norte (UFRN). Doutora em Administração pela Universidade Federal da Paraíba, Mestre e Bacharel em Administração pela UFRN.E-mail: valeriaraujo@ymail.com

2 Professora titular do Mestrado em Hospitalidade da Universidade Anhembi Morumbi. Livre docente em Teoria do Turismo e do Lazer, Doutora e Mestre em Ciências da Comunicação, e Bacharel em Turismo pela Universidade de São Paulo (USP). Professora associada (aposentada) da USP. Bolsista PQ do Conselho Nacional de Desenvolvimento Científico e Tecnológico. E-mail: mirwski@gmail.com

${ }^{3}$ Professor Adjunto do Departamento de Hotelaria e Turismo da Universidade Federal de Pernambuco (UFPE). Professor Colaborador do Programa de Pós-Graduação em Turismo da Universidade Federal do Rio Grande do Norte (UFRN). Doutor em Turismo pela Universidade de Surrey (Reino Unido), Mestre em Turismo pela Universidade James Cook (Austrália) e Bacharel em Turismo com MBA em Administração em Marketing de Serviços pela UFPE. E-mail: sergio.rleal@ufpe.br
} 
tourism in Brazil. In the first part, the text is based on the Business Administration literature, describing the case study method and the use of teaching case studies regarding conceptual aspects, tradition of application, as well as layout and viability. In the second part, it presents a case of Brazilian tourism with emphasis on Porto de Galinhas (PE), commenting on the evolution of this destination from the 1980s, the crisis faced with the cholera outbreak in the state of Pernambuco in the following decade, and the dilemma of the owner of a small lodging property while facing this crisis. In the end, it highlights the urgency for the elaboration of teaching cases about Brazilian tourism for the application in higher education programs along with scientific associations and journals in disseminating them amongst lecturers and researchers.

Keywords: Tourism; Higher education; Teaching cases; Teaching-learning; Porto de Galinhas (PE, Brazil).

Resumen: Un estudio exploratorio de la adecuación de los casos para la enseñanza en la educación superior como una estrategia para la enseñanza y el aprendizaje, con el fin de estimular a los profesores $e$ investigadores de Turismo para la construcción de los casos de turismo brasileño. En la primera parte, el texto se basa en una referencia del área de Administración, que describe el método de casos y el uso de casos de enseñanza en sus aspectos conceptuales, la tradición de la aplicación, y la forma y la viabilidad. En el segundo caso presenta un problema centrado en el turismo brasileño en Porto de Galinhas (PE), que trata de la evolución de este destino turístico a partir de la década de 1980, la crisis con la epidemia de cólera en el estado de Pernambuco, en la próxima década, y el dilema del propietario de una pequeña posada para hacer frente a esta crisis. Al final, pone de relieve la urgencia de la construcción de la enseñanza de los casos de turismo brasileño para su aplicación en la educación superior, junto con el papel de las asociaciones científicas y revistas en la difusión de lo mismo con los profesores e investigadores.

Palabras clave: El turismo; La educación superior; Casos de enseñanza; Enseñanza y aprendizaje; Porto de Galinhas (PE, Brasil).

\section{INTRODUÇÃO}

Em março de 2011, durante o I Seminário Internacional de Estudos Críticos em Turismo, na Universidade Federal do Rio Grande do Norte, em Natal (RN), foram discutidas diversas ações para a melhoria do ensino superior em Turismo no Brasil. Dentre essas, citou-se a falta de estudos sobre a realidade turística brasileira como estratégia de ensino-aprendizagem.

Tal estratégia, amplamente utilizada, principalmente nas universidades americanas e europeias, para a formação superior em áreas como a Administração, é denominada caso para ensino ou caso de ensino, cuja aplicação demanda um método do caso. Ao contrário, na área de Turismo, poucos docentes do país dominam esse método e o aplicam em sala de aula; quando o fazem, em geral, utilizam casos resumidos publicados em livros do exterior, por vezes traduzidos para o português, que não condizem com a realidade do turismo nacional, ou casos de ensino em outras áreas disciplinares.

Assim, surgiram vários questionamentos, tais como: como preparar os alunos de cursos de turismo para enfrentar os desafios profissionais, para tomarem decisões e aceitarem riscos de maneira segura? Como construir casos para ensino do turismo brasileiro? Há casos citados em salas de aula, ou apresentados em trabalhos acadêmicos, que poderiam ser "matéria-prima" para esses os mesmos? Quais os casos emblemáticos do Turismo brasileiro que deveriam estar registrados na literatura nacional? 
Preocupados com essas e outras perguntas, os autores deste artigo assumiram o compromisso conjunto de redigir um texto com o objetivo precípuo de chamar a atenção e estimular os docentes e pesquisadores de Turismo para a construção de casos para ensino. Inicialmente, tomou-se por base o livro Casos para Ensino em Administração, de Oliveira e Araújo (2010), e definiram-se os tópicos a serem desenvolvidos. Em seguida, desenvolveu-se uma breve fundamentação teórica, baseada especialmente na literatura sobre os casos em Administração, para a compreensão do seu conceito, tipologia, formato, vantagens e limitações. Por fim, escolheu-se uma situação do turismo brasileiro, a qual foi formatada como caso para ensino passível de utilização em cursos de graduação e pós-graduação em turismo.

Todo o texto foi sendo construído em conjunto, na forma de estudo exploratório, via comunicação online, em um desafio de reunir diferentes formações, opiniões e visões em um verdadeiro exercício de interdisciplinaridade.

\section{MÉTODO DO CASO E CASO DE ENSINO}

\section{Aspectos conceituais}

O método do caso é uma metodologia de ensino que descreve um problema real enfrentado por uma pessoa uma metodologia de ensino que descreve um problema real enfrentado por uma pessoa na organização, geralmente apresentado sob o ponto de vista do tomador de decisões, com o intuito de levar essa situação para um contexto de aprendizagem, convidando pessoas e alunos a refletirem e a se posicionarem diante do contexto apresentado.

Erskine e Leenders (2010) apontam que casos para ensino são descrições de uma situação atual, comumente envolvendo uma decisão, um desafio, uma oportunidade, um problema ou questão enfrentada por uma ou mais pessoas em determinada organização. Casos contêm relevantes dados, ou seja, informações mais detalhadas, sobre questões disponíveis a pessoas importantes que tomarão decisões na organização.

Para os autores, o método do caso é um método de instrução em que estudantes e instrutores fazem uma discussão direta de casos ou problemas organizacionais. Esses casos, geralmente preparados na forma escrita e derivados de experiências reais nas organizações, são lidos, estudados e discutidos pelos e entre os estudantes, e constituem-se na base para debates em classe com o acompanhamento do instrutor. O método do caso inclui, assim, um tipo especial de material instrucional e também técnicas especiais para o seu uso no processo de educação (Leenders, \& Erskine, 1989).

Outros autores abordam aspectos diferentes nos conceitos de casos de ensino. Para Ikeda, Veludo-de-Oliveira e Campomar (2006, p. 147) "o método do caso é uma estratégia de ensino baseada na apresentação de circunstâncias factíveis e/ou verídicas". Assim, os instrutores deverão selecionar casos relevantes e vinculados às disciplinas e às competências que se pretendem 
desenvolver no aluno, considerando ainda a possibilidade de apresentar um dilema que consiga transmitir com a máxima propriedade, ou seja, com toda a riqueza de detalhes da situação real vivenciada pelo tomador de decisões.

Na visão de Garvin (1991), casos são documentos de ensino que atendem dois objetivos: aplicação em uma aula e uma eficaz pedagogia. Percebe-se, assim, que o primeiro conceito valoriza e enfatiza como deve ser feita a elaboração e a construção dos casos, enquanto o segundo reflete os impactos da utilização dos casos no alcance dos objetivos educacionais e nos processos de aprendizagem.

Há ainda conceitos de casos para ensino considerados como mais abrangentes, por enfatizarem tanto aspectos vinculados à sua caracterização, quanto aos objetivos e à importância de utilização. Autores como Barnes, Christensen e Hansen (1994) consideram o caso para ensino como uma descrição de episódios práticos, selecionados da realidade, uma fatia da vida, uma estória designada e apresentada como material de estudo, um exercício, quebra-cabeça ou problema. Para Reynolds (1998, p. 520):

Um grupo é ensinado pelo método de caso quando participantes estudam uma situação anterior para discutirem o que deveriam estar fazendo e como deveriam fazer. O professor que usa o método do caso em aula é visto mais como um facilitador e encorajador da discussão e participação que um repositório da resposta correta.

Burgoyne e Mumford (1997, p. 9) possuem uma visão ainda mais completa sobre os casos para ensino, uma vez que descrevem as características, a importância da sua utilização e as formas de adotá-lo.

Uma descrição (em palavras ou em vídeo) de uma situação escrita especificamente com propósito do desenvolvimento, que existe ou existiu em uma organização. Alunos leem ou assistem um vídeo/filme e analisam o que aconteceu. Subsequentemente eles apresentam, debatem, defendem, discutem e criticam a análise, com tutores e outros alunos, em uma variedade de maneiras, como interação em pares, grupos ou sessões plenárias.

Em turismo, o método do caso também pode contribuir para o estudante se aproximar de diversas situações reais e complexas com as quais se defrontará em sua trajetória profissional, auxiliando diretamente na aproximação entre a teoria e a prática, como destacado por Oliveira e Araújo (2010) na área da Administração. Um exemplo é o livro editado na década de 1990 por Lewis (1997) nos Estados Unidos sobre casos de gestão e marketing em Hospitalidade, no qual são apresentados 16 casos de ensino envolvendo conceito, meio ambiente, estratégias operacionais e funcionais e aspectos integrados em diferentes hotéis e restaurantes, sendo um deles do Brasil.

Concorda-se com lizuka (2008), para quem esse método aproxima os alunos de uma tomada de decisão e dos dilemas do seu futuro cotidiano profissional, sendo diferente da forma 
tradicional de ensino ${ }^{4}$. Por outro lado, no método do caso, os alunos exercitam as suas habilidades de liderança, diante da tarefa a solucionar e dos desafios apresentados no caso. Assim, tanto as dúvidas e informações incompletas, como também a diversidade de posições das pessoas criam um ambiente adequado para que os alunos exerçam a sua capacidade em analisar, sintetizar, conciliar diferentes pontos de vista, propiciando a aprendizagem (lizuka, 2008).

Leenders e Erskine (1989, p. 14) reforçam essa ideia do aprendizado, alegando que:

No método do caso, os estudantes permitem-se cometer erros e aprendem com os mesmos porque não há grandes riscos envolvidos. Já na vida profissional, a tomada de decisão pode custar caro, pois um cargo, uma reputação ou a própria sobrevivência da empresa estão em jogo. Em essência, os casos são como cadáveres para estudantes de Medicina: a oportunidade de praticar os ensinamentos na vida real de forma inofensiva.

Reforça-se que, em turismo, os casos para ensino não devem se restringir apenas às organizações, já que podem descrever problemas e situações de desenvolvimento, planejamento e gestão de destinos, atrações, empresas ou empreendimentos turísticos, no passado recente ou no presente.

\section{Tradição de aplicação}

O método do caso aplicado ao ensino possui uma longa tradição, sendo usado pela primeira vez nos cursos de Direito Comercial, há mais de 100 anos, em 1908 na Harvard Business School (Roberts, 2004; Roesch, 2007). Nos anos seguintes, com o auxílio da pesquisa e do ensino desenvolvidos em Harvard, surgem os primeiros casos e livros sobre o assunto, por meio do apoio e da participação ativa dos professores que participaram das oficinas para a divulgação do ensino por meio de casos. No final dos anos 1920, surgiram as primeiras oficinas para a disseminação do ensino com a utilização de $\operatorname{casos}^{5}$.

Antes da Segunda Guerra Mundial, o acervo de casos para ensino em Harvard atingiu a marca de mais de 14 mil, e no final da década de 1930, esse acervo estava sendo adotado em cerca de 80 universidades americanas (Roberts, 2004).

Desde o início, a utilização de casos de ensino deu-se por meio de centrais que catalogam e regulam seu acesso, mediante o pagamento dos direitos autorais. Além disso, outras atividades são desenvolvidas por essas centrais, tais como o desenvolvimento de concursos para promover novos casos para ensino e a estruturação de oficinas para a construção de casos, ensinando professores a usarem casos em sala de aula (Roesch, 2007).

\footnotetext{
4 Nas metodologias de ensino tradicionais, o ensino é caracterizado por uma formação do tipo "bancária" (Freire, 1983), onde os estudantes recebem passivamente os fatos ou teorias, acumulando informações pouco ou nada críticas.

${ }^{5}$ Para outras informações sobre a origem do método do caso, ver artigo intitulado $O$ caso como estratégia de ensino na área de administração (Ikeda, Veludo-de-Oliveira, \& Campomar, 2006).
} 
Na Europa, o movimento só começou a surgir em 1930, inicialmente na França, com o apoio de Harvard e dos professores dessa instituição. Em seguida, o Reino Unido, como outros países da Europa, obtiveram o apoio de representações profissionais que colaboraram diretamente na disseminação do método.

Na European Case Clearing House (ECCH), situada na Universidade de Cranfield, Inglaterra, há um acervo de 20 mil casos de ensino. Destes casos, 60\% estão disponíveis no www.ecch.com/educators para as pessoas que se registram no sistema. As pessoas cadastradas podem também baixar no site da ECCH uma revista eletrônica bianual intitulada ECCH Overview (ECCHO) que contém resenhas de casos, artigos sobre como escrever casos, orientações para a utilização de casos nas atividades de ensino, como também notícias e informações sobre atividades vinculadas ao método do caso no mundo inteiro. Estatísticas da ECCH apontam que, apesar de $75 \%$ dos casos da instituição pertencer ao acervo de subsidiários da América do Norte e Europa, ocorreu um crescimento na internacionalização da redação de casos novos, uma vez que, no ano de 2003 , mais de $30 \%$ do total dos 1.300 casos novos foram originados de universidades da África e da Ásia.

No Brasil, a realidade apresentada é muito diferente se comparada com os Estados Unidos e a Europa. A Escola de Administração de Empresas de São Paulo da Fundação Getúlio Vargas (FGV-EAESP) foi a pioneira no país a utilizar a metodologia do caso na década de 1970. Nos anos seguintes, além dessa instituição, outras adotaram o método do caso nos moldes de Harvard (Roesch, 2007).

Entre os anos de 1975 a 1977, a Central Brasileira de Casos, ligada ao Instituto de PósGraduação e Pesquisa em Administração da Universidade Federal do Rio de Janeiro (COPPEADUFRJ) realizou, com o apoio do então Centro Brasileiro de Assistência Gerencial à Pequena e Média Empresa (CEBRAE), cinco seminários com um dos principais estudiosos no assunto, Michiel Leenders. Em 1973, o acervo da Central Brasileira de Casos era formado por 500 casos, dos quais, conforme ressalta lizuka (2008), apenas 30 eram casos brasileiros; no final de 1976, já havia 81 casos brasileiros.

Para Roesch e Fernandes (2006), apesar da bibliografia em português sobre o assunto ainda ser considerada como escassa, com uma produção insignificante de casos locais se comparada com o acervo de casos estrangeiros disponíveis, na atualidade há tentativas de estímulo ao ressurgimento e aplicação desse método, pelo menos da área de Administração: disseminação em instituições tradicionais de ensino superior; oferta de oficinas para a construção de casos; e a participação de professores brasileiros em cursos na Universidade de Harvard ou em estágios em outras instituições internacionais, além da participação em congressos internacionais (Roesch, 2007). Outras iniciativas a serem destacadas são: a publicação de casos de ensino na Revista de Administração Contemporânea (RAC), editada pela Associação Nacional de PósGraduação e Pesquisa em Administração (ANPAD) e o lançamento da primeira revista eletrônica voltada para casos de ensino a GVcasos - Revista Brasileira de Casos de Ensino em Administração, da FGV-EAESP, lançada por meio de parceria entre a RAE - Revista de Administração de Empresas 
e o CEDEA - Centro de Desenvolvimento do Ensino e da Aprendizagem, cuja missão é fomentar a produção e o uso de casos de ensino em Administração, contribuindo para a disseminação do uso de casos como metodologia de ensino e aprendizagem em cursos de graduação, pós-graduação, especialização e educação continuada.

Percebe-se, portanto, a importância de ações relevantes na área de Turismo, não apenas para estimular a construção de casos de ensino, quanto à sua aplicação em ambientes acadêmicos, envolvendo, por exemplo, o comportamento de turistas, os impactos turísticos nas comunidades locais, as relações entre hóspede e anfitrião, o ciclo de desenvolvimento de destinos turísticos, enfim, dilemas e problemas vivenciados por profissionais que atuam no turismo, tanto em organizações públicas quanto de propriedade privada.

Para tanto, é preciso compreender os tipos e formatos dessa estratégia de ensinoaprendizagem, tema do próximo tópico no qual se aproveita a experiência oriunda da área da Administração.

\section{Formatos, vantagens e limitações}

No Brasil, é comum que o método do caso seja confundido com o termo "estudo de caso". Para Ikeda, Veludo-de-Oliveira e Campomar (2005), esses conceitos são distintos. O estudo de caso é uma técnica de pesquisa qualitativa, que volta às atenções do pesquisador para o diagnóstico de uma situação particular, um ou mais "casos". O método do caso, por sua vez, possui finalidades pedagógicas, servindo, principalmente, para o desenvolvimento de habilidades nos estudantes, podendo inclusive ser elaborado a partir de um estudo de caso. Enquanto o estudo de caso refere-se à pesquisa científica, o método do caso aplica-se ao ensino.

Desta forma, os propósitos dos estudos de casos são diferentes das intenções dos casos para ensino. Para Yin (1989), um caso para ensino não necessita de uma versão completa ou de um evento real, utilizando-se de protocolos de atividades; sua finalidade é estabelecer uma estrutura para discussão e debate entre os estudantes.

Para Böcker (1987), os casos de ensino podem ser classificados em dois grupos: a) casosproblema, associados ao método do caso concebido na Universidade de Harvard, utilizados para levantar controvérsias, debates, fazer generalizações; b) casos-demonstração, utilizados para ilustrar aulas expositivas.

Autores como Goetz (1960), Kingsley (1982), Nuñez (2003), Lundberg et al. (2001), Kennedy et al. (2001), Naumes e Naumes (1999), Nelson (1996) e Harling e Akridge (1998) apontam que a tipologia de casos é bastante extensa, e, segundo Roesch, Fischer e Melo (2004), não há sequer uma definição consensual. Há vários tipos de casos que estão sendo adotados com diversos propósitos: casos-pesquisa e casos de ensino; casos práticos e casos teóricos; casos únicos e casos múltiplos. 
Os autores propõem uma tipologia para casos em gestão de quatro tipos: a) casos que buscam desenvolver conhecimento teórico e prático e são utilizados na pesquisa acadêmica para descrever e explicar os fenômenos, utilizando como parâmetro a base conceitual e a pesquisa empírica; b) casos práticos, que são utilizados para descrever ou difundir políticas e práticas de gestão; c) casos de ensino, que relatam problemas empresariais, com a finalidade de atingir objetivos educacionais; d) qualquer outro tipo de material ilustrativo utilizado em sala-de-aula. Destacam ainda que, apesar de todos os tipos de casos serem utilizados em sala-de-aula, apenas os casos para ensino são construídos com o propósito específico de utilização na mesma. Suas principais características formais quanto ao tamanho, objetivos, público-alvo, coleta de dados e estrutura do texto são apresentados no Quadro 1.

\begin{tabular}{|c|c|}
\hline Características & Casos para ensino \\
\hline Tamanho & - Máximo de oito a dez páginas de texto, espaço 1 , e até cinco páginas de anexos. \\
\hline Objetivos & $\begin{array}{l}\text { (Objetivos educacionais explícitos apenas nas notas de ensino) } \\
\text { - Desenvolver habilidades gerenciais. } \\
\text { - Ilustrar aulas expositivas. } \\
\text { - Informar sobre o contexto gerencial e organizacional. }\end{array}$ \\
\hline Público-alvo & - Alunos de determinado curso e nível de ensino. \\
\hline Coleta de dados & $\begin{array}{l}\text { - Planos de ensino. } \\
\text { - Coleta específica a uma organização de fatos, opiniões, números, documentos, } \\
\text { dados publicados, cenário, episódios, gestos, falas. }\end{array}$ \\
\hline $\begin{array}{l}\text { Estrutura do } \\
\text { texto }\end{array}$ & $\begin{array}{l}\text { - Narração da situação-problema do ponto de vista de um ou mais personagens } \\
\text { do caso. } \\
\text { - Descrição, sumário cronológico de eventos, uso de cenas e diálogos. } \\
\text { - Notas de ensino dirigida ao professor para uso do caso. }\end{array}$ \\
\hline
\end{tabular}

Quadro 1. Características formais do caso para ensino Fonte: Roesch e Fernandes (2007).

Miranda (2008, p. 29), ao estudar a avaliação de aprendizado por meio de casos de ensino em cursos de pós-graduação em negócios, descreve o processo de ensino-aprendizagem em três estágios, "de maneira a contribuir positivamente para o debate, e também para ajudar a alcançar um nível de compreensão mais minucioso sobre o caso": a) preparação individual: leitura de familiarização das informações, análise das informações, leituras complementares (conceitos e teorias), diagnóstico do problema, desenvolvimento de alternativas, definição de critérios, proposta de solução, proposição de um plano de ação; b) discussão em grupo, onde há oportunidade de debater os posicionamentos individuais e avançar o nível de compreensão; c) discussão em plenário, onde ocorre o desenvolvimento da compreensão completa e detalhada do 
caso $^{6}$. O autor ainda analisa a eficácia do uso desse método frente a vantagens e limitações, dentre as quais se elencam as apresentadas no Quadro 2.

\begin{tabular}{|c|c|}
\hline Vantagens & Limitações \\
\hline - Interesse em conhecer a teoria. & $\begin{array}{l}\text { Dificuldade com o uso do método ou com } \\
\text { alguma das suas fases. }\end{array}$ \\
\hline $\begin{array}{l}\text { - Espaço para a experiência dos alunos e seus } \\
\text { conhecimentos empíricos. }\end{array}$ & $\begin{array}{l}\text { Dificuldade do instrutor em conduzir o } \\
\text { método frente à personalidade ou } \\
\text { relacionamento entre os participantes. }\end{array}$ \\
\hline $\begin{array}{l}\text { - Oportunidade para apresentação e discussão } \\
\text { de soluções criativas. }\end{array}$ & $\begin{array}{l}\text { - Falta da percepção dos alunos em relação à } \\
\text { relevância do caso. }\end{array}$ \\
\hline $\begin{array}{l}\text { - Desenvolvimento de argumentação crítica } \\
\text { para a defesa de pontos de vista dos alunos. }\end{array}$ & $\begin{array}{l}\text { - Informações insuficientes sobre o caso, } \\
\text { comprometendo a sua compreensão e } \\
\text { debate. }\end{array}$ \\
\hline $\begin{array}{l}\text { - Descoberta e respeito por novas e diferentes } \\
\text { abordagens. }\end{array}$ & $\begin{array}{l}\text { - Ausência de conhecimento tácito da situação } \\
\text { durante o processo. }\end{array}$ \\
\hline $\begin{array}{l}\text { - Aprendizado na negociação e capacidade de } \\
\text { convencimento. }\end{array}$ & $\begin{array}{l}\text { - Falta de preparação prévia dos alunos sobre o } \\
\text { caso. }\end{array}$ \\
\hline - Realização de alianças e capacidade de ceder. & $\begin{array}{l}\text { - Ênfase exagerada no caso de ensino em } \\
\text { detrimento de outras estratégias de ensino- } \\
\text { aprendizagem. }\end{array}$ \\
\hline
\end{tabular}

\section{Quadro 2. Vantagens e limitações do uso de casos de ensino Fonte: Adaptado de Miranda (2008).}

Nos cursos de gestão do Brasil, o método do caso de Harvard ainda é pouco adotado. Utiliza-se amplamente a apresentação de casos-demonstração, que se assemelham ao caso exemplar, chamados em algumas vezes como cases ou cases empresariais. Estes relatam problemas, processos ou soluções quase universais e relevantes à maioria das organizações; o autor do caso tende a estar menos preocupado em criticar a realidade, sendo que algumas vezes ele está comprometido com a organização como participante ou consultor. Tais materiais ora são adotados nas aulas expositivas, ora são utilizados para a discussão em grupos, como por exemplo: artigos publicados na mídia, palestras de profissionais a respeito de suas experiências e histórias de sucesso de organizações (Roesch, \& Fernandes, 2006; Roesch, 2007).

No Brasil, uma das contribuições do caso-demonstração foi o projeto "Desenvolvendo Casos de Sucesso", do Serviço Brasileiro de Apoio à Pequena e Média Empresa (SEBRAE), que colaborou na produção de relatos de 80 casos exemplares entre os anos de 2002 e 2003.

\footnotetext{
${ }^{6}$ Esse processo de ensino-aprendizagem é descrito por Miranda (2008) com base em um quadro esquemático extraído do livro Learning with cases, de Louise A. Mauffette-Leenders, James A. Erskine e Michiel R. Leenders, editado pela Ivey Publishing no Canadá em 2001.
} 
Especificamente em turismo, tem-se a edição de um vídeo pelo Instituto Brasileiro de Turismo (EMBRATUR), em 1997, com os casos de sucesso do Programa Nacional de Municipalização do Turismo (PNMT), além de outros descritos em livros como Segmentação do Mercado Turístico, de Panosso Netto e Ansarah (2008) e o Turismo de Base Comunitária, de Bartholo, Sansolo e Bursztyn (2009).

No entanto, nenhum desses "casos turísticos" apresenta-se formatado como caso de ensino. Podem sim ser indicativos de "matérias-primas" a serem trabalhadas como tal. Nesse sentido também se lembra de inúmeros trabalhos de conclusão de curso, monografias de especialização ou até dissertações de mestrado, que tratam com propriedade de casos do turismo brasileiro a serem utilizados em salas de aula de forma mais eficiente se formatados como casos de ensino.

Tendo em vista o exposto neste item, e a fim de estimular a elaboração de casos de ensino em turismo, apresenta-se a seguir um exemplo de caso problema sobre a recuperação da crise de Porto de Galinhas face ao surto de cólera no estado de Pernambuco, na década de 1990.

\section{RECUPERAÇÃO DE CRISE: O CASO DA ASSOCIAÇÃO DE HOTÉIS DE PORTO DE GALINHAS}

\section{Introdução}

Pai e filho conversam sobre o rumo que a empresa da família deve tomar. O filho, que estudou na capital e se considera mais capacitado do que o pai, tem uma opinião bem formada sobre qual caminho deve ser tomado. Já o pai, empreendedor sem nenhuma formação acadêmica, vê com desconfiança a solução que se apresenta para os problemas que vem enfrentando.

\section{História de Fernando}

Fernando era um pescador, nascido e criado na, então, pacata Vila de Pescadores de Porto de Galinhas. Durante sua infância e adolescência, aprendeu com seu pai, seu avô e seus tios a arte da pesca. Além dos peixes e frutos do mar que eram consumidos por ele e sua família, os excedentes eram vendidos a comerciantes locais e a eventuais visitantes que desafiavam as péssimas condições das estradas de terra batida para conhecer as belezas naturais que a região tinha a oferecer.

No início da década de 1980, Fernando viu uma movimentação diferente nos arredores da vila de pescadores. Percebeu que pessoas da capital visitavam a área com mais frequência; algumas delas até com certa periodicidade. Foi quando, em meados da década, ficou sabendo que um hotel seria construído numa praia perto da sua Vila. Não conhecia o Recife, mas sabia que a capital do estado também era banhada pelo mar. Achou estranho e se perguntou: "Quem se daria ao trabalho de enfrentar uma estrada de terra batida e esburacada para ver uma praia?". 


\section{Início da atividade turística em Porto de Galinhas}

Porto de Galinhas localiza-se no município pernambucano de Ipojuca, a cerca de $60 \mathrm{~km}$ da capital, Recife. Até o início da década de 1980, era praticamente conhecida apenas pelos moradores da localidade e por alguns poucos pernambucanos que possuíam casa de veraneio na região.

Com a inauguração do Hotel Solar Porto de Galinhas, em 1986, Fernando ficou surpreso com o número de pessoas que passaram a visitar não só a praia e o hotel, mas a própria Vila onde ele havia morado por toda a sua vida. As pessoas queriam saber como era o estilo de vida dos pescadores e queriam comer pratos feitos com peixes e frutos do mar frescos. Quando um segundo hotel foi inaugurado, o Village Porto de Galinhas, em 1988, a rotina de Fernando e de parte da sua família já havia sido alterada. Eles continuavam pescando. Mas, agora, dividiam o seu tempo para, também, fazer passeios de jangada com os turistas, para preparar e servir pratos típicos da culinária local, e para realizar outras atividades até então inimagináveis para os pescadores da Vila.

Com o grande fluxo de pessoas nas praias onde os pescadores encontravam os peixes e frutos do mar, a pesca ficou mais difícil. Havia a necessidade de se deslocar para áreas não exploradas pelo turismo para encontrá-los. Alguns amigos de Fernando acabaram abandonando a pesca por completo e se dedicando às atividades criadas a partir da visitação gerada pelos hotéis, pois vislumbraram uma oportunidade de maior ganho financeiro com menor esforço que a pesca. Pequenas pousadas começaram a surgir para complementar a oferta de hospedagem existente. Com o passar do tempo, novos hotéis foram se instalando e a infraestrutura básica (estradas, esgotamento sanitário, fornecimento de energia elétrica etc.) começou a tentar acompanhar o ritmo de crescimento do destino, pois neste momento não se tratava mais de uma simples vila de pescadores e sim de um destino turístico.

\section{Pousada do Fernando}

Em 1990, já com o turismo se consolidando no destino, Fernando também decidiu abandonar a pesca e se dedicar, exclusivamente, ao turismo. Passou a hospedar visitantes em sua própria casa. Com o passar do tempo foi construindo novos aposentos no terreno da casa e, finalmente, no ano seguinte, abriu a Pousada do Fernando. Seu filho, Márcio, já não tinha aprendido a arte da pesca como ele. Sabia pescar, mas era bom mesmo no contato com os turistas e na prestação de serviços, informais, de guia de turismo. Quando fez 16 anos, Fernando resolveu mandá-lo para o Recife, onde teria a oportunidade de estudar turismo. Márcio fez um curso técnico na área e voltou cheio de ideias. 


\section{Crise e resposta dos hoteleiros}

Tudo ia de vento em poupa quando, em 1992, um surto de cólera assolou diversos países sul-americanos, inclusive o Brasil. Como medida de contenção da doença, o governo de Pernambuco proibiu o banho de mar e o consumo de peixes e frutos do mar. Assim, a atividade turística praticamente deixou de acontecer no estado. Porto de Galinhas sofreu os impactos gerados por esta crise do setor e os donos de hotéis e pousadas precisaram buscar alternativas para a resolução deste problema.

Foi aí que cinco hoteleiros resolveram unir esforços e fundar a Associação de Hotéis de Porto de Galinhas (AHPG). Esta associação surgiu como resposta à crise do turismo pernambucano, deflagrada pela proliferação da cólera no estado. Os hotéis de Porto de Galinhas ficaram vazios por meses e, para tentar reverter a situação, resolveram unir forças com o objetivo de divulgar e fortalecer não só os seus empreendimentos mas o destino como um todo.

Até então, o público-alvo dos hotéis era formado por turistas do próprio estado de Pernambuco, estados vizinhos e região nordeste. Após a criação da AHPG, este passou para as regiões sudeste, centro-oeste e sul do país, ficando o nordeste em segundo plano. A partir de 1996, o destino Porto de Galinhas passou a ser divulgado e comercializado no exterior, mediante a presença da AHPG em algumas das principais feiras de turismo de Portugal e da Argentina, inicialmente. Hoje, esta participação vai além desses países e, por meio de parcerias com a Secretaria de Turismo, Esportes e Cultura do Ipojuca, o destino e os meios de hospedagem (não só os que fazem parte da Associação) são divulgados e comercializados em alguns dos principais mercados emissores do mundo.

\section{Dilema de Fernando}

A Pousada do Fernando não era associada à AHPG, mas, mesmo assim, ele se beneficiou das ações desenvolvidas, uma vez que estas tiveram o destino como foco e não exclusivamente os hotéis associados. Fernando começou a se questionar se valeria à pena iniciar contatos com os fundadores da AHPG para se associar. A sua dúvida surgiu pelo fato de que ele tinha apenas uma pequena pousada enquanto os hotéis associados eram de médio a grande porte. Será que ele seria mais beneficiado como membro associado ou, de qualquer forma, já estava se beneficiando e não havia esta necessidade? Além disso, para ser associado, teria que trabalhar em parceria com aqueles que considerava serem os seus maiores competidores.

Fernando chamou Márcio para discutirem a questão e começou dizendo: "Você estudou na capital... o que acha dessa tal associação? Será que podemos, e devemos, fazer parte dela? Será que a gente tem cacife para isso?"

Márcio riu e comentou: “Cacife, eu não sei! Mas, sei que podemos nos beneficiar bastante com a parceria com os outros meios de hospedagem". 
Fernando, novamente, levantou uma das questões que o preocupava: "Mas eles são nossos principais concorrentes!".

Sem nenhum receio, seu filho citou um provérbio muito famoso no nordeste: "Uma andorinha só não faz verão. Precisamos que todos os envolvidos com a atividade turística se unam para reverter essa situação de crise pela qual estamos passando. Se isso significa unir forças com concorrentes, assim terá que ser".

Ainda incrédulo, Fernando resmungou: "Você diz isso porque era muito pequeno quando comecei a montar a pousada e não se lembra das dificuldades que eu e sua mãe tivemos que enfrentar para competir com aqueles que vinham da capital ou até de fora do estado com bastante dinheiro no bolso e com equipes de trabalho montadas. Nós éramos apenas um casal alugando um quarto enquanto eles tinham uma estrutura consolidada".

Unir forças com os seus competidores ou esperar que os benefícios gerados para o destino se reflitam na sua pousada? Fernando estava cético sobre a parceria com os concorrentes. Já Márcio estava seguro de que era a única opção para reverter a situação gerada pelo surto de cólera. Uma decisão precisava ser tomada imediatamente para garantir a sobrevivência da pousada no curto prazo.

\section{Notas de ensino}

Resumo: O desenvolvimento do turismo em Porto de Galinhas se deu em meados da década de 1980, quando os primeiros hotéis se instalaram na região. Ex-pescadores passaram a trabalhar na atividade turística e um deles, Fernando, abriu uma pousada. A atividade turística se desenvolveu rapidamente, mas, uma crise foi deflagrada pelo surto de cólera que assolou o país em 1992. Tal crise estimulou a criação da Associação de Hotéis de Porto de Galinhas (AHPG) por parte de cinco hoteleiros da região. O dilema de Fernando é se ele deve se associar aos seus concorrentes para enfrentar a crise ou se deve esperar que as ações da AHPG fossem suficientes para salvar o destino e, consequentemente, a sua pousada.

\section{Objetivos de aprendizagem:}

Ao final da leitura, os alunos deverão ser capazes de atingir os seguintes objetivos: a) verificar a complexidade do turismo através dos impactos sofridos a partir de uma questão de saúde pública; b) avaliar, com base nos aspectos positivos e negativos de cada alternativa, qual a melhor estratégia para a empresa; c) exercitar a prática de tomada de decisões na gestão de empresas; d) conhecer a prática do associativismo no turismo como forma de recuperação em crises.

Obtenção dos dados: Os dados sobre o desenvolvimento do turismo em Porto de Galinhas e sobre a criação e atuação da AHPG para a elaboração deste caso de ensino foram obtidos por meio de mensagens eletrônicas da secretaria da Associação. Já os dados sobre Fernando, Márcio e a pousada da família são fictícios. 


\section{Questões para discussão:}

1. Debata a complexidade da atividade turística com base no caso do surto de cólera de 1992, em Pernambuco.

2. Se você fosse Fernando, aceitaria o conselho do seu filho e tentaria se associar à AHPG? Por quê?

3. Você acredita que a formação de uma associação possa realmente reverter uma situação de crise como a enfrentada pelos hotéis de Porto de Galinhas? Justifique.

Análise do caso: Os alunos podem iniciar a discussão do caso debatendo sobre a complexidade envolvida na atividade turística. No turismo, potencializa-se esse contexto, pois o processo de produção e de consumo turístico é, essencialmente, um sistema interdependente de relações entre pessoas e de múltiplas organizações. Trata-se de um fenômeno complexo, com incertezas, imprevisibilidades, turbulências e mudanças (Silva, 2011).

A complexidade da atividade turística pode ser constatada nos impactos econômicos negativos que o surto de cólera gerou para todos os envolvidos. Embora, geralmente, não se tenha a saúde pública como item prioritário dos gestores públicos e privados do turismo, trata-se de um tema indispensável para o bom andamento da atividade em qualquer destino. Da mesma forma, questões de cunho social, ambiental, entre outras, devem ser consideradas na gestão do turismo, pois podem, direta ou indiretamente, afetar o desenvolvimento da atividade.

Assim, pode ser destacado que o turismo, embora seja uma atividade essencialmente privada, é, na sua gestão, altamente dependente do poder público e demais setores da sociedade/comunidade. Essa característica do segmento turístico se reflete diretamente na articulação entre os setores público e privado, sem a qual a atividade não pode ocorrer. Essa característica peculiar do turismo deve ser levada em consideração por parte dos gestores que atuam no segmento, buscando uma aproximação entre as várias organizações de diferentes setores da economia que recebem os reflexos das atividades turísticas na demanda dos seus serviços. Dados da Organização Mundial do Turismo (OMT) destacam que o turismo impacta e é impactado por 52 setores da economia.

Beni (2001) afirma que, para compreender melhor o turismo e o papel do setor público com relação a ele, uma abordagem que oferece uma perspectiva integradora baseia-se na teoria dos sistemas. A teoria do Sistema de Turismo (Sistur) é composta por três grandes conjuntos: o das relações ambientais, o da organização estrutural e o das ações operacionais, como também seus elementos ou subsistemas (ecológico, econômico, social e cultural, da superestrutura, da infraestrutura, do mercado, da oferta, da demanda, de produção, de distribuição e de consumo) e as relações de interação entre eles.

Assim, a partir do entendimento do turismo como uma atividade complexa, os alunos podem evidenciar a importância de um dos principais desafios do turismo - a implementação de modelos de gestão adequados e eficazes. Tais modelos devem proporcionar desenvolvimento nas dimensões econômica, social e cultural, a exemplo da função de administração do Sistur, 
compreendida como a criação e execução de planos que envolvem o desenvolvimento do turismo considerando a melhoria do bem estar das pessoas por meio da geração de oportunidades de negócios, emprego e renda, sem comprometer as condições de vida das gerações atuais e futuras.

Para Hall (2001), o planejamento e a gestão das ações no turismo devem promover a construção de processos integrados orientados à satisfação das necessidades das várias partes interessadas, apresentando mecanismos que impliquem na participação e envolvimento dos diversos setores ligados, direta ou indiretamente, à atividade turística e à necessidade de se desenvolver métodos e planos de ação para acompanhar continuamente as ações planejadas.

Mesmo com todo o planejamento turístico, há situações de crise em que o controle da situação foge às decisões organizacionais. Desta forma, as soluções para os problemas enfrentados se tornam quase impossíveis. No entanto, através da união de forças, diversas empresas juntas podem conseguir reverter a situação. Nem sempre isto é possível. Mas, a formação de uma associação permite que o melhor de cada empresa seja colocado na mesa de discussões para que se busquem as soluções possíveis para os problemas.

Assim, a associação é uma das estratégias utilizadas pelas organizações para se fortalecerem em um ambiente de alta incerteza, onde uma ou mais organizações se unem com o propósito de estabelecer uma ação conjunta, para minimizar a instabilidade ambiental, atenuando a competição e dependência entre as organizações.

Embora os empresários brasileiros frequentemente vislumbrem seus concorrentes apenas como competidores, há setores, como o turismo, onde a parceria é peça fundamental para o sucesso. 0 insucesso de um empreendimento turístico, por vezes, afeta a imagem do destino, sendo negativo para todos os outros empreendimentos por lá instalados. O sucesso do destino se traduz no sucesso dos estabelecimentos de hospedagem, de alimentação e de outros serviços receptivos. Assim, a filiação da Pousada do Fernando à AHPG seria benéfica para a empresa.

\section{Referências consultadas}

Beni, M. C. (2001). Análise estrutural do turismo. (2ª ed.). São Paulo: SENAC.

Hall, C. (2001). Planejamento turístico: políticas, processos e relacionamentos. São Paulo: Contexto.

Silva, Q. P. da. (2011). A lógica do caos como parâmetro para a gestão do Turismo: contribuições e aplicabilidades. Dissertação de Mestrado, Universidade Federal do Rio Grande do Norte, Natal, RN, Brasil.

\section{CONSIDERAÇÕES FINAIS}

Este artigo tratou da construção e aplicação de casos de ensino como uma estratégia de ensino-aprendizagem a ser estimulada em cursos superiores de Turismo, uma vez que são poucos 
os docentes que a empregam. Com base no referencial do tema na área de Administração, onde tal estratégia vem sendo utilizada desde a década de 1920, apresentou diferentes conceitos sobre o método de caso e o caso de ensino ou para ensino, distinguindo-o do estudo de caso, seus diferentes tipos, em geral reduzidos a casos-problema e casos-demonstração, e suas vantagens e limitações.

Percebeu-se que os casos de ensino em Turismo carecem de aplicação nos cursos superiores da área, principalmente pela falta de casos não apenas de organizações turísticas, mas também de destinos, atrações, empreendimentos e situações turísticas. Mesmo considerando que há casos de organizações turísticas em bancos de cases ou em periódicos de outras áreas, notadamente da Administração, estes não se adéquam ao desenvolvimento de conteúdos disciplinares de cursos de Turismo. Assim, há necessidade tanto da construção de casos de ensino com foco na realidade do turismo brasileiro, quanto de cursos que orientem docentes para a sua adequada aplicação e a publicação de casos em periódicos da área.

A descrição do caso de Porto de Galinhas, com foco na estória da trajetória de um pequeno empreendedor a enfrentar uma crise causada pelo surto de cólera no início dos anos de 1990, ilustra uma situação ocorrida em um conhecido destino turístico brasileiro, como um exemplo a ser multiplicado para tantos outros destinos, situações ou organizações. Espera-se que a publicação deste artigo motive os pesquisadores e docentes da área a se dedicarem ao exercício da descrição, análise e interpretação da realidade turística brasileira por meio de casos de ensino. Quiçá em um futuro próximo o docente de cursos de Turismo tenha acesso a farto material para o desenvolvimento do aprendizado de seus alunos!

\section{REFERÊNCIAS}

Barnes, L. B., Christensen, C. R., \& Hansen, A. J. (Eds.). (1994). Teaching and the case method. (3a ed.). Boston: Harvard Business School Press.

Bartholo, R, Sansolo, D. G., \& Bursztyn, I. (Org.). (2009). Turismo de base comunitária. Diversidade de olhares e experiências brasileiras. Rio de Janeiro: Letra e Imagem.

Böcker, F. (1987). Is case teaching more effective than lecture teaching in business administration? An exploratory analysis. Interfaces, 17(5), 64-71.

Burgoyne, J, \& Mumford, A. (1997). Learning from the case method: a report to the european case clearing house. England.

Erskine, J. A., \& Leenders, M. R. (2010). Learning with cases. Recuperado em 10 novembro, 2010, de www.cases.ivey.uwo.ca.

EUROPEAN Case Clearing House. [online]. Recuperado em 6 abril, 2011, de http://www.ecch.com.

Freire, P. (1983). Educação "bancária" e educação libertadora. In Patto, M. H. de S. (Org.). Introdução à psicologia escolar. São Paulo: T. A. Queiroz. 
Garvin, D. A. (1991). Operations Strategy: Text and Cases. Englewood Cliffs, N. J.: Prentice Hall.

Goetz, B. E. (1960). Ways of learning. Industrial Management Review, 1(1), 9-15.

Harling, K. F., \& Akridge, J. (1998). Using the case method of teaching. Agribusiness, 14(1), 1-14.

lizuka, E. S. (2008). O método do caso de Harvard: reflexões sobre sua pertinência ao contexto brasileiro. Anais do Encontro da Associação Nacional dos Programas de Pós-Graduação em Administração, Rio de Janeiro, RJ, Brasil, 22.

Ikeda, A. A., Veludo-de-Oliveira, T., \& Campomar, M. C. (2005). A tipologia do método do caso em administração: usos e aplicações. Revista O\&S, 12(34).

Ikeda, A. A., Veludo-de-Oliveira, T., \& Campomar, M. C. (2006). O Caso como estratégia de ensino na área de Administração. Revista de Administração, 41(2), 147-157.

Kennedy, E. J., Lawton, L., \& Walker, E. (2001). The case for using live cases: shifting the paradigm in marketing education. Journal of Marketing Education, 23(2), 145-151.

Kingsley, L. (1982). The case method as a form of communication. The Journal of Business Communication, 19(2), 39-50.

Leenders, M. R., \& Erskine, J. (1989). Case research: the case writing process. London/Ontario: Research and Publication Division/School of Business Administration.

Lewis, R. C. (1997). Cases in hospitality marketing and management. New York: John Wiley.

Lundberg, C. et al. (2001). Case writing reconsidered. Journal of Management Education, 25(4), 450-463.

Miranda, R. C. (2008). Avaliação de aprendizado através de casos de ensino em cursos de pós-graduação em negócios. Dissertação de Mestrado, IBMEC, Rio de Janeiro, RJ, Brasil.

Naumes, W., \& Naumes, M. J. (1999). The art \& craft of case writing. Thousand Oaks: Sage Publications.

Nelson, E. (1996). Producing and using case material for research and teaching: a workshop for partners in know-how transfer projects. Journal of European Industrial Training, 20(8), 22-30.

Nuñez, A. M. (2003). El estudio de casos: un enfoque cognitivo. México, D. F.: Trilla.

Oliveira, P. W. S., \& Araújo, M. V. P. (2010). Casos para ensino em administração. Curitiba: CRV.

Panosso Netto, A., \& Ansarah, M. (2008). Segmentação do mercado turístico. Estudos, produtos e perspectivas. Barueri: Manole.

Reynolds, J. I. (1998). Case method in management development: guide for effective use. Geneva: International Labor Office. (Management Development Series, n. 17).

Roberts, K. (2004). Case development in Europe - an historical perspective. ECCHO - The Newsletter of the European Case Clearing House, n. 32. Recuperado em 8 fevereiro, 2012, de http://www.ecch.com/about/back-issues.cfm.

Roesch, S. M. A., \& Fernandes, F. (2007). Como escrever casos para o ensino de administração. São Paulo: Atlas.

Roesch, S. M. A., \& Fernandes, F. (2006). Notas sobre a construção de casos para ensino. Anais do Encontro da Associação Nacional dos Programas de Pós-Graduação em Administração, Salvador, BA, Brasil, 20.

Roesch, S. M. A., Fischer, T., \& Melo, V. P. (Org.). (2004). A construção de casos em gestão social: diferenças entre estudos de caso e casos de ensino. Gestão social para o desenvolvimento: casos para o ensino.

Cadernos de Gestão Social, 1, 1-12. 
Roesch, S. M. (2007). Notas sobre a construção de casos para ensino. Revista de Administração Contemporânea, 11(2), 213-234. (Doi: 10.1590/S1415-65552007000200012)

YIN, R. K. (1989). Case study research: design and methods. London: Sage.

Artigo recebido em: 23/02/2012. Artigo aprovado em: 21/04/2012. 